\title{
Incapacidade Funcional e Ambiente Suburbano: Proposta de Tipologia para uma Relação Difícil
}

\author{
Jorge Manuel Gonçalves ${ }^{a}$ Marta Castilho Gomes ${ }^{a}$ Luís Carvalhob \\ Sofia Ezequiel ${ }^{\mathrm{a}}$ \\ ${ }^{a}$ CERIS - Investigação e Inovação em Engenharia Civil para a Sustentabilidade, Instituto Superior Técnico, \\ Universidade de Lisboa, Lisbon, Portugal; bCIAUD - Centro de Investigação em Arquitetura, Urbanismo e Design, \\ Faculdade de Arquitetura, Universidade de Lisboa, Lisbon, Portugal
}

\section{Palavras Chave}

Subúrbios · Incapacidade funcional · Urbanismo ·

Planeamento urbano

\section{Resumo}

Introdução: Pretendeu-se conhecer a desigual distribuição dos indivíduos que apresentam incapacidades funcionais ligadas à audição, à visão e ao andar no espaço suburbano de Lisboa. Métodos: A articulação entre variáveis e unidades territoriais resultou numa tipologia que ajuda a diferenciar estes territórios e, finalmente, permitiu a criação de uma cartografia suburbana que relaciona, nas áreas mais problemáticas, episódios de incapacidade funcional e urbanismo. Resultados: Das 40 variáveis recolhidas verificou-se que com apenas oito foi possível descrever a realidade das 26 freguesias que apresentam uma taxa de risco bastante acima da média na concentração de pessoas com dificuldades funcionais. Estas freguesias estão assimetricamente distribuídas: 10 no norte e 16 no sul da Área Metropolitana. A aplicação da análise de clusters permitiu diferenciar estas freguesias em quatro tipos distintos: polarizador e envelhecido; desqualificado e residencial; antigo e rural; pouco acessível e diverso. Conclusão: Considera-se que os resultados obtidos a partir da investigação desenvolvida contribuem para o reforço do conhecimento do efeito acelerador ou inibidor do urbanismo na integração de populações com incapacidades funcionais e para a formulação de políticas urbanas mais adequadas, eficazes mas também diferenciadas, visando a inclusão sociourbana destes indivíduos.

(c) 2017 The Author(s). Published by S. Karger AG, Basel on behalf of Escola Nacional de Saúde Pública

\section{Functional Disabilities and Suburban Environment: Proposal of a Typology for a Difficult Relationship}

\section{Keywords}

Suburbs · Functional disabilities · Urbanism · Urban planning

\section{Abstract \\ Introduction: In this article, the unequal distribution of individuals with functional disabilities linked to hearing vision, and walking in the suburban area of Lisbon was studied. Methods: The relationship between variables and territorial units resulted in a typology that helps dif- ferentiate these territories and, finally, allowed the cre- ation of a map of the suburbs that correlates episodes of}

\section{KARGER}

E-Mail karger@karger.com www.karger.com/pjp

Karger

Open access (c) 2017 The Author(s). Published by S. Karger AG, Basel on behalf of Escola Nacional de Saúde Pública

This article is licensed under the Creative Commons AttributionNonCommercial-NoDerivatives 4.0 International License (CC BYNC-ND) (http://www.karger.com/Services/OpenAccessLicense). Usage and distribution for commercial purposes as well as any distribution of modified material requires written permission.
Jorge Manuel Gonçalves, $\mathrm{PhD}$

CERIS - Investigação e Inovação em Engenharia Civil para a Sustentabilidade Instituto Superior Técnico, Universidade de Lisboa

PT-1049-001 Lisbon (Portugal)

E-Mail jorgemgoncalves@ @ecnico.ulisboa.pt 
functional disability and urbanism in the troubled areas. Results: From the 40 variables collected, only 8 were able to describe the reality of the 26 parishes that present a risk rate well above the average concentration of people with functional difficulties. These parishes are asymmetrically distributed: 10 in the north and 16 in the south of the metropolitan area. The methodology of cluster analysis allowed differentiating these parishes into 4 different types: polarizer and aging; disqualified and residential; old and rural; less accessible and diverse. Conclusion: We consider that the results obtained from the developed research may contribute to further the knowledge of the effects of urbanism as a factor in promoting or inhibiting the integration of people with functional disabilities, and thus in the design of more appropriate, effective but also differentiated urban policies aimed at the social and urban inclusion of these individuals.

(0) 2017 The Author(s). Published by S. Karger AG, Basel on behalf of Escola Nacional de Saúde Pública

\section{Introdução}

O mundo assiste a uma transição profunda que se desenvolve a partir das mudanças urbanas e demográficas. Dada a sua relevância podemos falar mesmo de duas transições que concorrem para a grande transformação do planeta habitado [1]: Em 2050, por via da transição demográfica, os indivíduos com mais de 60 anos podem chegar aos dois mil milhões estando em cerca de $80 \%$ dos casos em países desenvolvidos [2]; por outro lado, a transição urbana está refletida no facto de que a partir de 2007 mais de metade da população do planeta passou a viver em cidades sendo que essa tendência continua muito clara sobretudo em países em desenvolvimento $[3,4]$.

A conjugação de um mundo urbano com um mundo mais idoso acarreta novas preocupações quer com os indivíduos quer com os ambientes de vida quotidiana onde se movem [5-8].

Steels [1] revelou recentemente a existência de uma ampla investigação feita já neste século sobre estes domínios, sistematizando os principais modelos e quadros de análise construídos reveladores da riqueza das abordagens produzidas. A vasta revisão da literatura que levou a efeito culminou na identificação das características-chave que uma cidade ou comunidade age-friendly deveriam evidenciar, designadamente, a cooperação entre stakeholders, a inclusão de pessoas idosas, ou o empenho dos decisores politicos, entre outras.

Incapacidade Funcional e Ambiente Suburbano
Algumas cidades são estruturalmente mais adequadas para indivíduos que vão revelando uma progressiva diminuição das suas capacidades funcionais mas, tanto nesse caso como nas que exigem uma urgente requalificação urbana, as intervenções urbanas necessárias acabam por ter de ser múltiplas gerando importantes fatores de tensão [9].

As preocupações derivadas das incapacidades funcionais ligadas a dificuldades de visão, audição e andar no quotidiano dos cidadãos que residem em espaços urbanizados justificam-se quer pelas limitações que podem significar para a vida dos indivíduos [10] quer pelo que podem representar em termos de qualidade da cidade que estamos a considerar.

O International Transport Forum (ITF) [11] sublinha a todo o momento a relevância da pedonalidade e sobretudo do seu exercício para a condição física dos indivíduos, para a sua socialização e inclusão social e para a sua autonomia funcional. Numa outra perspetiva, a promoção deste tipo de mobilidade, que é gratuita e livre de emissões nocivas para o ambiente, faz diminuir o tráfego motorizado, torna as cidades mais amigáveis e vividas e permite uma partilha de usos mais equilibrada. Contudo, de acordo com o ITF [11] mais de 400 mil peões morrem anualmente no mundo devido a acidentes com viaturas motorizadas. O ITF [11] revela ainda que, apesar da população com mais de 65 anos ser inferior a 20\% do total, é a que mais se vê, em cerca de $50 \%$ dos casos, envolvida nestas fatalidades.

Uma das ideias de partida centrais para esta investigação é que as incapacidades funcionais dos indivíduos foram sobretudo adquiridas ao longo da vida mas, naturalmente, de forma mais acelerada a partir de idades mais avançadas. Todavia, esta pesquisa centrou-se nos indivíduos com incapacidades funcionais independentemente da sua idade e até da possibilidade da incapacidade indicada ser apenas temporária. Uma segunda ideia liga-se ao facto de não se considerar, neste caso, o contexto como responsável pelo aprofundamento daquelas incapacidades, mas sim pelo alastramento das suas consequências na qualidade de vida dos indivíduos. É também claro que estas determinantes individuais conjugadas com determinantes contextuais desfavoráveis não só têm impacto na vida quotidiana, gerando mais incómodos e limitações, como poderão vir a afetar a saúde do indivíduo através da "falta de controlo, baixa autoestima, stress, isolamento social, ansiedade e solidão" [12].

Todavia, a aferição da qualidade do contexto não passa, neste caso concreto, pela consideração do modelo de amplificação da privação dos lugares enunciado por Ma- 
cintyre et al. [13] que se caracteriza por uma desqualificação do contexto urbano, ambiental e social. Aliás, Nogueira [12] deixa bem claro que a tendência é generalizada ou, como afirma, "há um círculo vicioso de degradação dos lugares que amplifica a vulnerabilidade individual, no qual a privação tem um papel-chave." Na mesma linha parecem seguir o trabalho de investigação desenvolvido por Ribeiro et al. $[14,15]$ onde se aponta para uma tendência de melhoria da condição física dos indivíduos, designadamente dos idosos, em contextos urbanos mais qualificados ou, de forma mais precisa, quando estes oferecem parques e espaços de lazer de proximidade. A consequência mais óbvia destas condições urbanas é a de permitir o adiamento das limitações físicas que tendencialmente surgem em pessoas de idade mais avançada.

Esta desigualdade metropolitana, que se desdobra em muitos outros domínios, não poderia deixar de se fazer sentir na saúde dos seus residentes [16]: por um lado, impondo problemas aos seus utilizadores mais frequentes pelas condições ambientais, sociais e urbanas que lhes proporciona [17]; por outro lado, e é nesta perspetiva que nos situamos, em relação às limitações físicas pré-sentidas pelos seus residentes, isto é, agravando-as no caso de má qualidade ou atenuando-as no caso de espaços qualificados [18].

A adequação do espaço urbano à multiplicidade dos seus utilizadores deriva muito dos princípios que presidiram à sua concepção. Como afirma Gonçalves et al. [19]:

O espaço metropolitano de Lisboa registou ciclos de expansão-retração quase sempre comandados pela forma como a capital foi reagindo ao quadro económico e financeiro internacional e nacional. Os ciclos de expansão e de retração não se materializam sempre do mesmo modo. No caso dos primeiros é possível encontrarse desde a habitação coletiva e unifamiliar de génese clandestina até a muitos outros formatos de construção de espaço urbano bastante mais qualificados; no caso do segundo os mais óbvios relacionam-se com um grande universo de devolutos, vazios urbanos, espaços degradados, por exemplo.

Entre uns e outros é fácil perceber como o quadro de vida dos utilizadores das cidades pode ser afetado em especial se registarem um determinado grau de incapacidade funcional [20].

Para além destes aspetos importa ainda referir um outro com o qual este tema se relaciona de forma muito intensa: o envelhecimento da população. Com efeito, a parte da esperança média de vida passada sem incapacidade funcional foi medida em Portugal para os anos de $1995 / 1996$ [21, 22] em apenas $44 \%$ para as mulheres e $57 \%$ para os homens, com idades compreendidas entre os 65 e os 69 anos. No caso da população com 85 e mais anos essa percentagem da esperança média de vida atravessada sem limitações reduzia-se para $19 \%$ nas mulheres e $28 \%$ nos homens.

Esta realidade portuguesa, onde um pouco mais de metade das mulheres e um pouco menos de metade dos homens com idades entre os 65 e os 69 anos de idade já revelavam alguma incapacidade funcional continua, já em pleno século XXI, a revelar-se preocupante e a justificar uma cuidada atenção. Com efeito, em 2014 e em média as mulheres portuguesas passam 55,4 anos de vida saudáveis e os homens 59,8 anos. Dez anos antes, 2004, essas idades eram de 52,4 e 55,4 anos, respetivamente. Apesar de se pressentir uma evolução lenta, mas positiva no sentido de um envelhecimento mais saudável, Portugal ainda está muito distante, por exemplo, dos 74,3 anos (mulheres) e 72,3 anos (homens) de vida saudável registados em 2014 pela população de Malta [23].

Sendo um processo generalizado nas sociedades ocidentais o envelhecimento é especialmente claro na realidade portuguesa. Com efeito, as estimativas do Instituto Nacional de Estatística (INE) apontam para 2.111.822 indivíduos em Portugal com 65 e mais anos em 2015. O peso deste grupo no conjunto da população residente no país era, assim, de 21,2\%. A comparação com o início deste século (2001) dá-nos a possibilidade de avaliarmos o ritmo a que se tem processado a evolução da situação. Nessa altura eram 1.705.274 os idosos recenseados pelo INE representando $16,5 \%$ dos habitantes no país.

Este processo de envelhecimento que atinge hoje um quinto da população está, portanto, a sofrer um agravamento acelerado independentemente da perspetiva adoptada. Por exemplo, se se utilizar agora o índice de envelhecimento (pop. $>64$ anos/pop. $<15$ anos) para Portugal, verifica-se que se em 2001 a relação média era de 101,6 idosos por cada 100 jovens, em 2015 esse valor passou para 148,3 .

Se agora se atentar no caso concreto da Área Metropolitana de Lisboa a realidade é muito próxima em 2015 da situação nacional. Os 587.299 indivíduos com 65 e mais anos correspondiam, neste ano, a uma proporção no universo demográfico metropolitano de 20.9\%. Em 2001 essa relação era apenas de $15,5 \%$. Por outras palavras, nesta década e meia a AML passou de uma situação mais favorável para outra em que o envelhecimento se tornou ainda mais grave que o que se verifica no país, através de uma transição muito rápida.

Quando se analisa o índice de envelhecimento a situação em 2015 é mais favorável mas continua a ser muito convergente com a realidade nacional (131 idosos por cada 100 jovens), quando em 2001 essa relação era apenas de 102.
Gonçalves/Castilho Gomes/Carvalho/ Ezequiel 
Assim, o envelhecimento da população, que está muito articulado com a multiplicação dos casos de incapacidade funcional, continua em expansão no país e na Área Metropolitana de Lisboa, confirmando a oportunidade que esta investigação pode trazer para um maior conhecimento da sua relação com o espaço urbano.

Uma última constatação, também útil para a compreensão da pesquisa aqui desenvolvida, relaciona-se com o fato de na pesquisa bibliográfica não se ter encontrado material científico relevante debruçado sobre este tópico da incapacidade funcional na sua articulação com as características dos contextos arquitetónico e urbanístico.

Pretende-se, assim, refletir sobre a desigual distribuição, no espaço suburbano de Lisboa, das ocorrências de incapacidades funcionais ligadas à audição, à visão e ao andar, demonstrando que as maiores concentrações existentes se localizam em quadros urbanos e arquitectónicos que ora os agravam, pela ausência de condições adequadas, ora os atenuam pelas razões inversas.

Merece um destaque especial a opção pelo estudo da periferia de Lisboa já que os trabalhos de investigação e outros de cariz mais técnico realizados na Área Metropolitana de Lisboa (AML) ou se debruçam sobre a cidade de Lisboa ou sobre a AML no seu todo ou ainda, eventualmente, sobre algum dos seus concelhos. Neste caso concreto considerou-se a AML sem a cidade de Lisboa por três razões essenciais:

(i) Esta pesquisa insere-se numa linha de investigação sobre periferias que pretende trazer um renovado olhar sobre os subúrbios da capital portuguesa.

(ii) Interesse em apontar o foco para um território que muito poucas vezes surge de forma autónoma e que agora, atendendo ao envelhecimento das estruturas demográficas, à fragilização das estruturas sociais e familiares e ainda à desqualificação dos espaços urbanos, merece um olhar mais atento.

(iii) A exclusão de Lisboa do estudo subtrai quase 20\% da população da AML com condições mais favoráveis de acesso a serviços e equipamentos, permitindo um retrato da realidade mais interessante e objetivo.

Em consequência do objetivo central de conhecer a distribuição das ocorrências das incapacidades funcionais na sua relação com o urbanismo surge de imediato um outro, complementar, ligado à abordagem das implicações resultantes, relacionadas com a necessidade de hierarquizar as intervenções tendentes à melhoria do edificado e do espaço público de modo a dar prioridade às áreas que concentram os maiores problemas [24].

\section{Metodologia}

Como informação de base recorreu-se aos Censos de 2011 que, no questionário dirigido aos indivíduos, pretendia averiguar o seu grau de dificuldade diário na realização de algumas atividades. Os indivíduos poderiam referir de acordo com o questionário dificuldades em ver, ouvir, andar ou subir degraus, memória ou de concentração, em tomar banho ou vestir-se sozinho e ainda em compreender os outros ou fazer-se entender. Existindo três categorias de resposta possíveis neste estudo recorreu-se apenas aos indivíduos que manifestavam muita dificuldade ou limitação absoluta perante as três primeiras incapacidades funcionais referidas atrás.

Neste caso concreto foram usadas as variáveis que consideram a população com incapacidade funcional de ouvir, ver e andar mas também outras reunidas pela dimensão social (população com mais de 65 anos, população com mais de 75 anos, qualificações escolares) e pela dimensão urbanística (edifícios quanto à existência de elevadores e acesso a cadeiras de rodas, tipo de uso de edifício, idade do edificado e ainda necessidade de reparação).

Foram ainda considerados dois indicadores que não resultaram diretamente dos Censos: o índice de atropelamento que utiliza dados do INE para as vítimas de atropelamento e para o número total de residentes; e a compacidade do meio urbano que resulta da combinação do número de edifícios proveniente dos Censos com áreas urbanas medidas sobre a cartografia de uso do solo do projeto Corine Land Cover 2012.

Estas variáveis foram obtidas para as 158 freguesias dos concelhos da AML constituintes do que se designou como periferia de Lisboa, isto é, de todos os concelhos da AML excluindo o concelho de Lisboa (Fig. 1).

Tendo em consideração as principais preocupações referidas para a investigação adoptou-se a proposta metodológica contida em Gonçalves et al. [25], entendendo-se-se que a abordagem deveria ser feita através do seu desdobramento em objetivos operacionais:

- Cruzar os epicentros dos episódios das incapacidades funcionais - globalmente e desagregadas - com variáveis demográficas (população por grupos etários) e sociais (habilitações escolares).

- Mapear a informação relativa às características dos edifícios e do espaço urbano que sejam relevantes. Neste contexto surgem as variáveis relativas aos edifícios sem elevador e com dificuldades de acesso em cadeira de rodas; para os segundos considerou-se pertinente utilizar a informação relativa à presença da função residencial no edifício, idade do edificado e às necessidades de reparação.

A análise das variáveis recolhidas foi efetuada em dois passos. Num primeiro, a análise concentrou-se nas 158 freguesias recolhendo a informação constante da Tabela 1.

Para a caracterização da distribuição espacial destas variáveis na Área Metropolitana de Lisboa (sem Lisboa), apuraram-se medidas de síntese para cada uma; determinou-se a matriz de correlação (que mede o grau de associação linear entre pares de variáveis - análise bivariada); e fez-se uma análise factorial de componentes principais - ACP, recorrendo ao pacote de software Statistica ${ }^{\circledR}$ version 12. Para o cálculo da matriz de correlação e a ACP analisaramse as 158 freguesias mas utilizaram-se apenas 34 variáveis, por terem sido excluídas as seis variáveis expressas em número absoluto dado que não permitem comparações. 


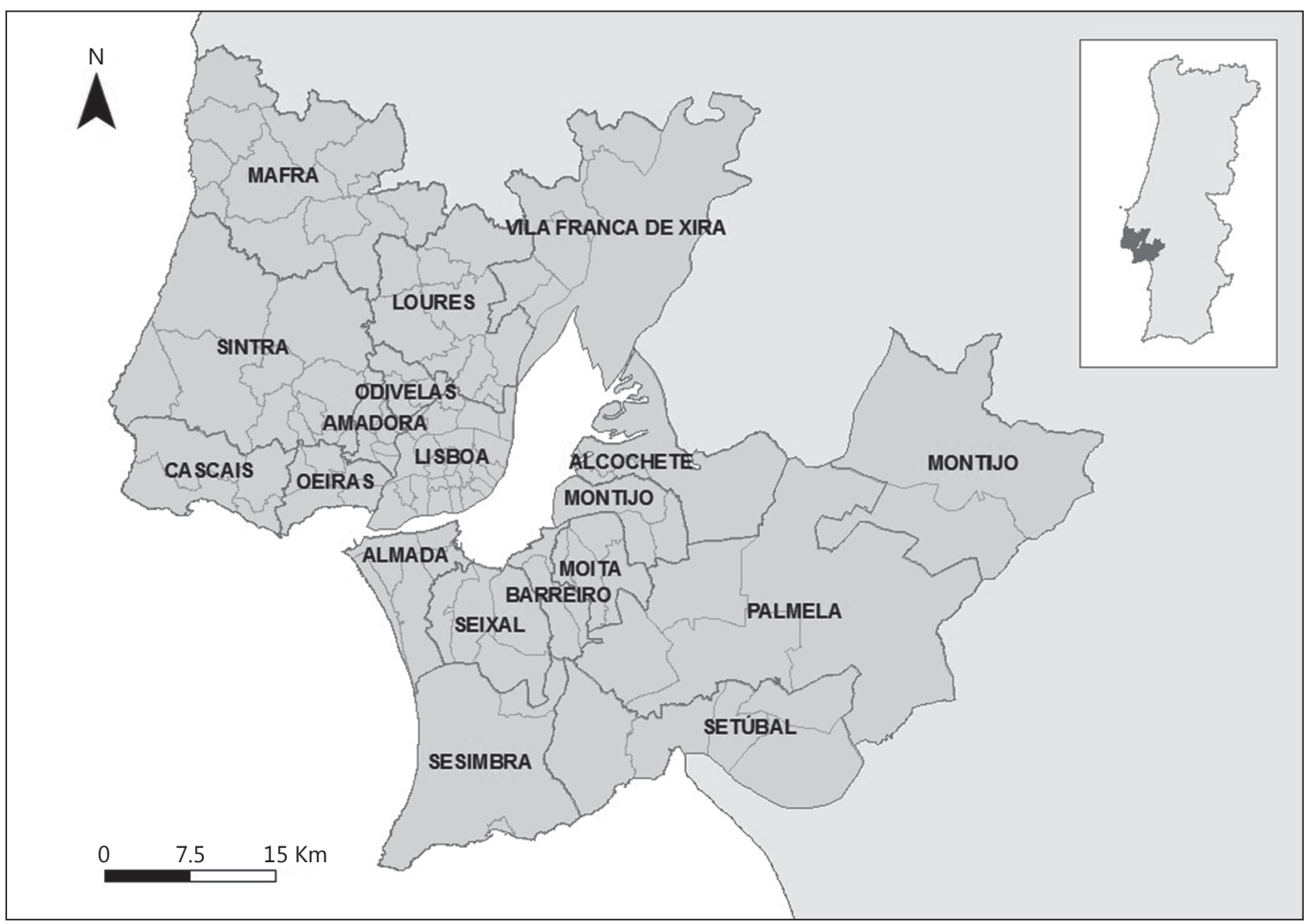

Fig. 1. Identificação dos concelhos da Área Metropolitana de Lisboa e dos respetivos limites municipais e de freguesia

Observados os resultados do primeiro passo da metodologia o segundo compreendeu as seguintes etapas:

1. As 12 variáveis iniciais relativas a incapacidades, que já tinham sido reduzidas a seis para a análise de correlação e ACP, foram agora reduzidas a uma (cf. o passo seguinte). Resultaram assim, para a segunda fase da metodologia, 29 variáveis no total.

2. Foi determinado o quociente entre a soma dos três tipos de incapacidade (dificuldade em ver, ouvir ou andar) e o triplo da população residente (que corresponde ao potencial máximo de ocorrência de incapacidades funcionais em cada freguesia) exprimindo, assim, a intensidade dos episódios de incapacidade funcional por freguesia.

3. De seguida procedeu-se à identificação das freguesias onde se verifica uma maior concentração de ocorrências de incapacidades funcionais. Para tal, foi feita uma análise relacionando o valor da percentagem de episódios de incapacidades em cada freguesia com o valor médio e o desvio padrão das 158 freguesias consideradas. Com base nesta análise encontraram-se as freguesias cuja intensidade de episódios de incapacidades funcionais estava acima do valor da média mais um desvio padrão.

4. Isolando estas freguesias, ou seja as que registam maior incidência de incapacidades na Área Metropolitana de Lisboa (sem Lisboa), foi possível submetê-las a uma segunda ACP com o objetivo de identificar, de entre as 29 variáveis agora consideradas, quais aquelas que melhor caracterizam estas freguesias.
Assim, aplicou-se a ACP com extração de um número variável de componentes e analisaram-se as matrizes dos pesos fatoriais resultantes, com vista à utilização desta informação para a análise de clusters. Concluiu-se que a extração de três componentes foi a que resultou num melhor equilíbrio entre a percentagem de variância explicada e um valor significativo dos pesos fatoriais.

5. O último passo deste processo foi a realização de uma análise de clusters, aplicada às freguesias selecionadas devido ao maior peso dos episódios de incapacidades, com base nas variáveis selecionadas no passo anterior. Esta análise permitiu definir tipologias de áreas/freguesias de acordo com as características dos indivíduos e do meio urbano, relacionadas com as suas incapacidades.

\section{Resultados}

Dos resultados obtidos na primeira fase da metodologia destacam-se as diferenças observadas entre a média das variáveis das percentagens da população com muita dificuldade em ver, em ouvir ou em andar e a das variáveis das percentagens da população que não vê, não ouve ou 
Table 1. Variáveis recolhidas

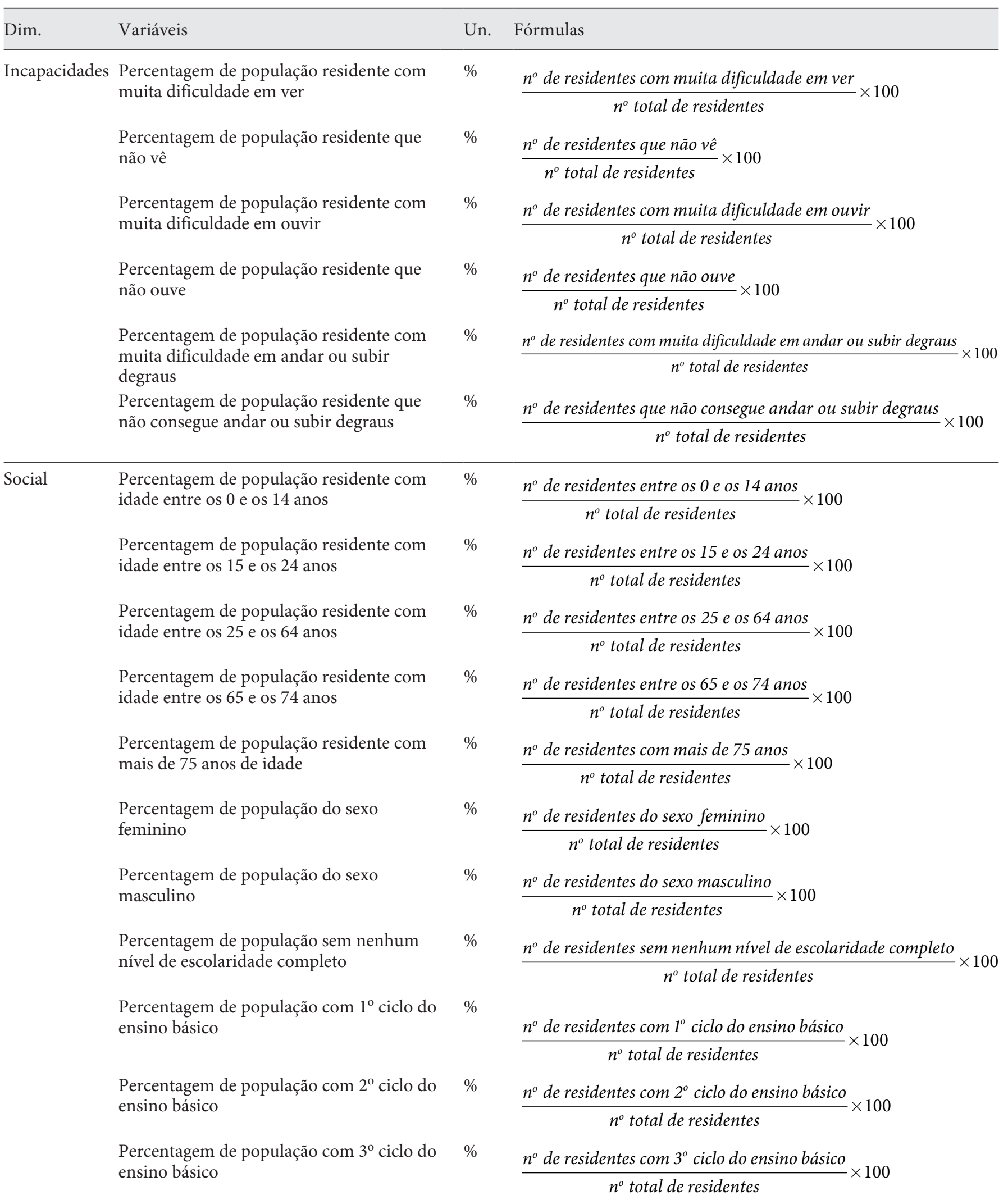


Table 1 (continued)

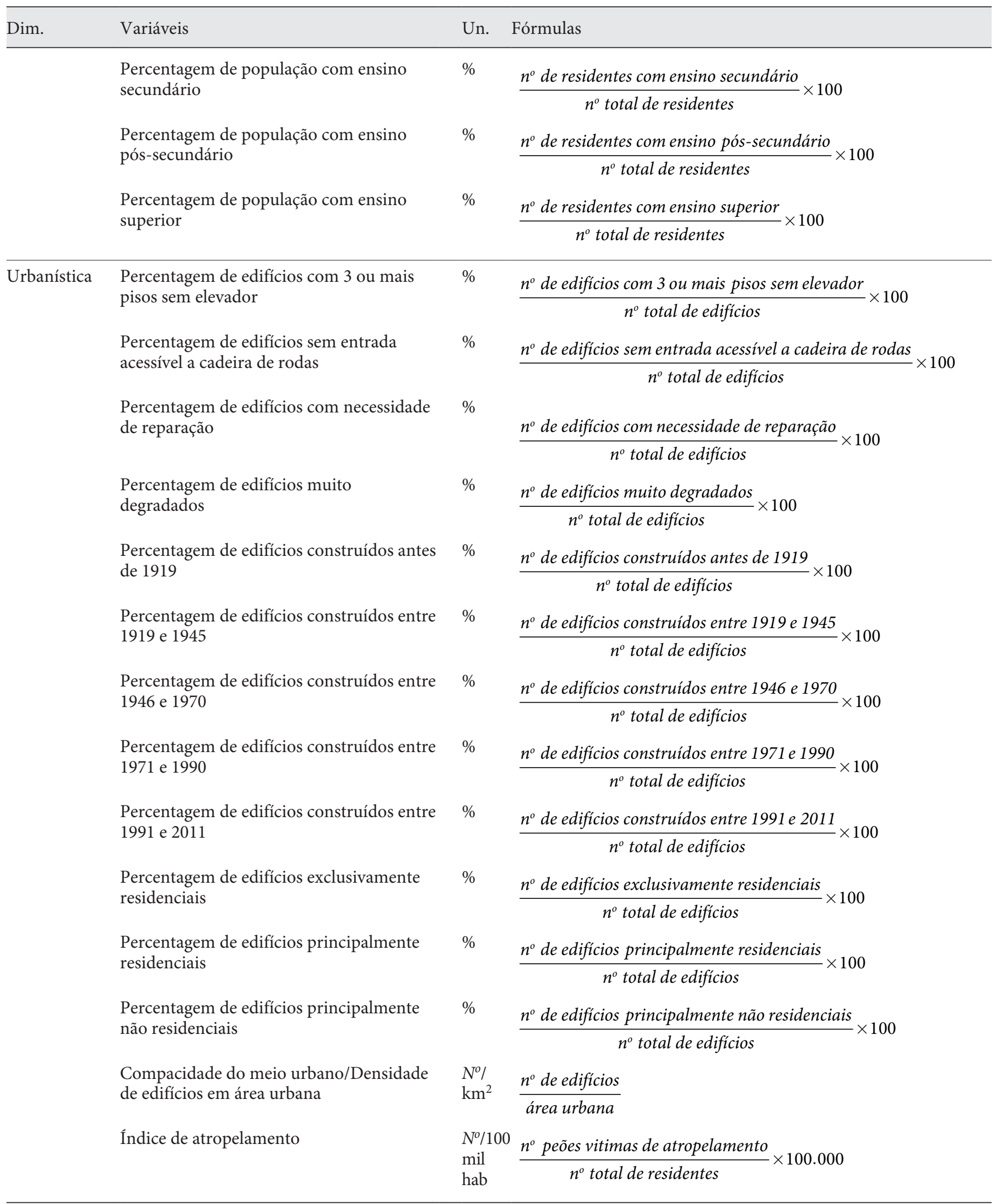


Table 2. Matriz de correlação para as variáveis ligadas às incapacidades funcionais e coeficientes de correlação entre as variáveis ligadas às incapacidades funcionais e as restantes variáveis

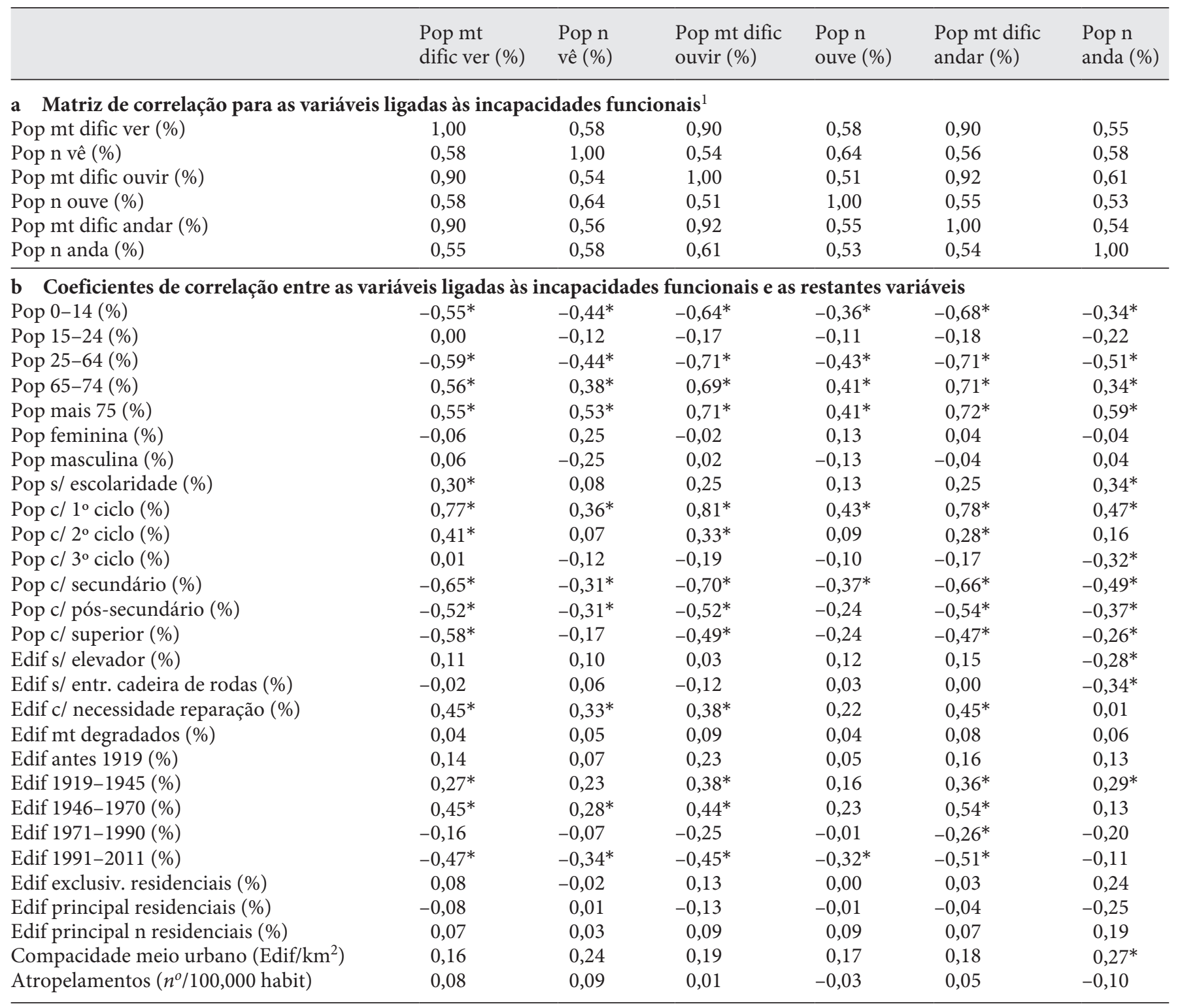

${ }^{1}$ Todas as correlações são significativas para $p<0,001$. ${ }^{*}$ As correlações são significativas para $p<0,001$.

não anda (adiante designadas por incapacidades absolutas), para o conjunto das 158 freguesias estudadas. Enquanto a média das primeiras variáveis está compreendida entre 4 e $7 \%$ da população da freguesia, a média das segundas situa-se entre 0,3 e $0,8 \%$ da população. Relativamente à associação com as restantes variáveis (considerando como nível de significância $p<0,001$ ), o comportamento do grupo de variáveis ligado às dificuldades fun- cionais e o do grupo de variáveis das incapacidades absolutas é bastante diferente. Em síntese, observou-se que:

- As variáveis da população com dificuldades apresentam maior correlação entre si do que as variáveis das incapacidades absolutas (Tabela 2a). As primeiras estão também mais correlacionadas com as faixas etárias da população e com o grau de instrução do que as se- 
gundas (Tabela 2b). Isto traduz uma concentração mais forte das dificuldades em ver, ouvir e andar na população mais velha (e menos instruída em média), não se verificando tal concentração com as incapacidades absolutas.

- A percentagem da população com muita dificuldade em andar está correlacionada com a percentagem de edifícios com necessidade de reparação $(r=0,45, p<$ $0,001)$, com a percentagem de edifícios construídos entre 1919 e $1945(r=0,36, p<0,001)$ e com a percentagem de edifícios construídos entre 1946 e 1970 $(r=0,54, p<0,001)$. Não há correlação com a percentagem de edifícios sem entrada para cadeira de rodas $(r=0,00, p<0,001)$ ou sem elevador $(r=0,15, p<$ 0,001 ) (Tabela $2 b$ ).

- A percentagem da população que não anda não está correlacionada com a percentagem de edifícios com necessidade de reparação $(r=0,01, p<0,001)$ nem com a percentagem de edifícios construídos entre $1946 \mathrm{e}$ $1970(r=0,13, p<0,001)$ mas está correlacionada com a percentagem de edifícios construídos entre 1919 e $1945(r=0,29, p<0,001)$. Há correlação com a percentagem de edifícios sem entrada para cadeira de rodas ou sem elevador $(r=-0,34$ e $-0,28$, respetivamente, $p<0,001)$. Estes valores negativos para a correlação significam que em freguesias com maior percentagem de edifícios de um ou de outro tipo, a percentagem da população que não anda é menor (Tabela $2 b$ ).

- Nas freguesias de construção mais recente há um menor peso de pessoas com episódios de incapacidade funcional dada a correlação negativa entre a percentagem de edifícios construídos entre 1991-2011 com a percentagem de população com muita dificuldade em $\operatorname{ver}(r=-0,47, p<0,001)$, em ouvir $(r=-0,47, p>0,001)$ e andar $(r=-0,51, p<0,001)$ (Tabela $2 \mathrm{~b}$ ).

- Estes resultados justificam a opção de, na segunda fase da metodologia, concentrar o estudo apenas na população com dificuldades funcionais em ver, ouvir e andar.

Os resultados expostos pela Tabela $2 \mathrm{~b}$ comprovam que a percentagem de população dos 0 aos 14 anos e dos 25 aos 64 anos assim como a percentagem dos indivíduos com o ensino secundário revelam uma correlação significativa e negativa com todas as variáveis relativas aos episódios de incapacidade funcional. De modo inverso, isto é, correlacionando-se com estes de modo significativo e positivo, surgem a percentagem de população dos 65 aos 74 anos, a percentagem de população com mais de 75 anos e a percentagem de população com apenas o $1^{\circ}$ ciclo de escolaridade.
A ACP permitiu condensar a informação das variáveis em quatro componentes ortogonais, não relacionados entre si, retendo $65 \%$ da variância explicada. A componente 1 traduz as dificuldades em ver, ouvir ou andar e a idade da população; a componente 2 a função dos edifícios e condições de acessibilidade; a componente 3 os níveis de escolaridade da população; e a componente 4 a idade dos edifícios.

Apresenta-se na Figura 2 o cartograma que territorializa a intensidade dos episódios de incapacidades funcionais na Área Metropolitana de Lisboa (AML).

$O$ resultado desta análise para o conjunto de 158 freguesias da AML (sem Lisboa) revelou que 23 encontramse no intervalo abaixo da "média - desvio padrão" sendo que 21 se localizam na margem norte e apenas duas na margem sul (Fig. 2).

No outro extremo surgem as freguesias com maior concentração de episódios de dificuldades funcionais, ou seja, as que registam valores acima da "média + desvio padrão" (24,2\%) (Fig. 2). São 26 freguesias sendo que dez se localizam na margem norte e 16 na margem sul da AML, denunciando uma maior concentração de ocorrências destes casos na AML-Sul.

Assim, numa leitura imediata da Tabela 3 constata-se que quase metade do total das 26 freguesias com maior concentração de episódios de dificuldades funcionais (percentagem superior à "média + desvio padrão") encontram-se em apenas três concelhos da margem sul: Barreiro, Montijo e Almada.

Hierarquizando as 26 freguesias por ordem decrescente do peso relativo das ocorrências de incapacidades verifica-se que:

- No conjunto das freguesias consideradas verificam-se quase 47.000 ocorrências de incapacidades funcionais (num total de aproximadamente 174.300 residentes) o que determina uma intensidade a rondar os $9 \%$.

- Em cada uma das 14 primeiras freguesias observam-se mais de 1.000 episódios de incapacidades funcionais, informação que consta na Tabela 5 .

- As nove freguesias com mais episódios com incapacidades funcionais localizam-se todas na margem sul sendo que sete são integrantes de concelhos do Arco Ribeirinho Sul (Almada, Barreiro, Moita e Montijo).

- Em duas freguesias - Baixa da Banheira e Alto do Seixalinho - ocorrem, em cada uma delas - mais de 5.000 episódios de incapacidades funcionais.

- De notar que nas freguesias do Alto do Seixalinho e de Verderena, hoje formando uma só freguesia devido a uma reorganização administrativa, observam-se quase 8.200 episódios de dificuldades funcionais.
Gonçalves/Castilho Gomes/Carvalho/ Ezequiel 


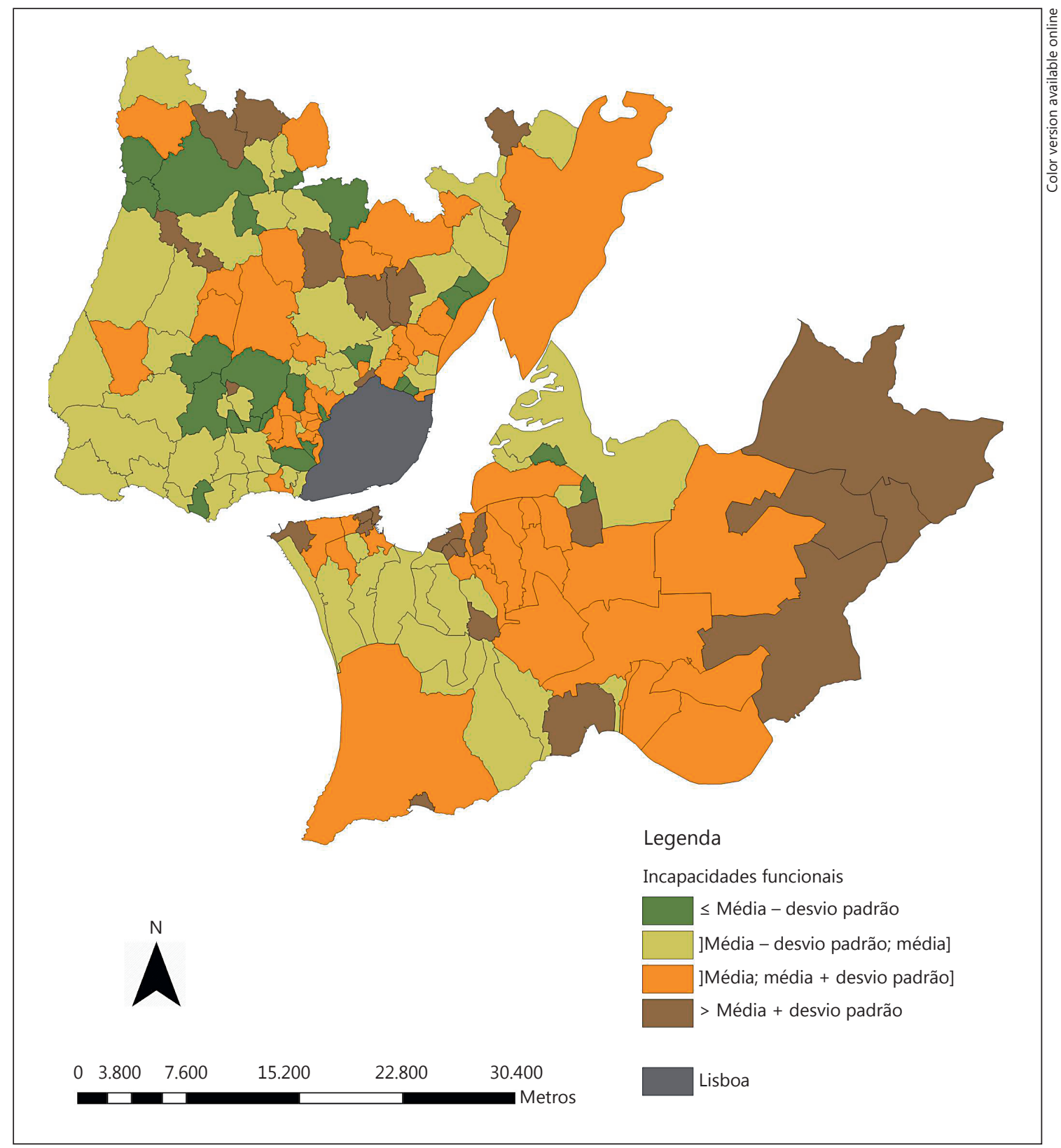

Fig. 2. Concentração por freguesia das ocorrências de incapacidades funcionais, na AML.

A extração de três componentes principais, na ACP realizada com as 26 freguesias identificadas no passo anterior, retém $63,2 \%$ da variância dos dados[26] recomendando-se um limiar mínimo de $60 \%$ em estudos com variáveis de natureza socioeconómica. Após efetuar uma rotação varimax normalizada (para melhorar os valores dos pesos factoriais), verifica-se que a componente 1 explica $35,9 \%$ da variância dos dados, a compo- nente 2 explica $14,9 \%$ e a componente 3 explica $12,4 \%$ da mesma.

Em seguida, selecionaram-se oito variáveis a partir da matriz dos pesos factoriais para estas três componentes: quatro variáveis para a componente 1 (por explicar aproximadamente o dobro da variância), duas variáveis para a componente 2 e duas variáveis para a componente 3 . 
Table 3. Freguesias que acolhem a maior concentração relativa das ocorrências de incapacidades funcionais

\begin{tabular}{|c|c|c|c|}
\hline Ordem & Freguesia & Concelho & $\begin{array}{l}\text { Intensidade de } \\
\text { incapacidades } \\
\text { funcionais, } \%\end{array}$ \\
\hline 1 & Sesimbra (Santiago) & Sesimbra & 12,59 \\
\hline 2 & Canha & Montijo & 11,58 \\
\hline 3 & Almada & Almada & 9,91 \\
\hline 4 & Alto-Estanqueiro-Jardia & Montijo & 9,58 \\
\hline 5 & Coina & Barreiro & 9,43 \\
\hline 6 & Pegões & Montijo & 9,28 \\
\hline 7 & Mira-Sintra & Sintra & 9,27 \\
\hline 8 & Setúbal (Nossa Senhora da Anunciada) & Setúbal & 9,24 \\
\hline 9 & Alto do Seixalinho & Barreiro & 9,07 \\
\hline 10 & Trafaria & Almada & 9,02 \\
\hline 11 & Verderena & Barreiro & 8,90 \\
\hline 12 & Baixa da Banheira & Moita & 8,76 \\
\hline 13 & Lousa & Loures & 8,61 \\
\hline 14 & Cheleiros & Mafra & 8,56 \\
\hline 15 & Santo Isidro de Pegões & Montijo & 8,45 \\
\hline 16 & Cachoeiras & Vila Franca de Xira & 8,44 \\
\hline 17 & Azueira & Mafra & 8,42 \\
\hline 18 & São Julião do Tojal & Loures & 8,38 \\
\hline 19 & Cacilhas & Almada & 8,37 \\
\hline 20 & Alhandra & Vila Franca de Xira & 8,33 \\
\hline 21 & Cova da Piedade & Almada & 8,30 \\
\hline 22 & Santo Antão do Tojal & Loures & 8,27 \\
\hline 23 & Barreiro & Barreiro & 8,20 \\
\hline 24 & Olival de Basto & Odivelas & 8,17 \\
\hline 25 & Sobral da Abelheira & Mafra & 8,16 \\
\hline 26 & Marateca & Palmela & 8,15 \\
\hline
\end{tabular}

Optou-se por selecionar um conjunto de variáveis representativas das 29 variáveis em vez de usar diretamente as componentes principais na análise de clusters. Esta opção decorreu do facto de que no caso do subconjunto de 26 freguesias qualquer das componentes principais misturava variáveis caracterizadoras da população e do edificado, não apresentando uma interpretação "limpa" como aconteceu na aplicação da ACP para as 158 freguesias.

A seleção foi efectuada conjugando dois critérios: (i) escolher de entre as variáveis com maiores pesos factoriais em cada componente, e para que este não fosse inferior a 0,65 (em valor absoluto); (ii) ter representado cada "tema" das variáveis no conjunto final.

As variáveis selecionadas no primeiro e segundo passo e respectivo domínio foram as que a Tabela 4 resume. De notar que das 8 variáveis que compõem as três componentes quatro caracterizam a população e quatro o edificado.
As oito variáveis escolhidas foram depois estandardizadas pelo método $z$-score (somente no conjunto das 26 freguesias) para homogeneização das escalas, e efetuou-se em primeiro lugar uma análise de clusters hierárquica. Esta indicou três ou quatro clusters como o número mais adequado, consoante se aplique o método de agregação complete linkage (do vizinho mais afastado) ou de Ward (Fig. 3).

Aplicou-se em seguida o método não-hierárquico $k$ means, que é um método de optimização da distribuição das entidades (freguesias), para quatro clusters.

Os quatro clusters obtidos através do método $k$-means são justificados a partir do comportamento diferenciado das oito variáveis. A distribuição espacial das 26 freguesias organizadas pelos quatro clusters está ilustrada pela Figura 4 e descrita na Tabela 5.

Foi possível avançar com designações para cada cluster que, de alguma forma, sugerissem uma imagem mais clara que a que seria dada apenas pelos valores das variá-
Gonçalves/Castilho Gomes/Carvalho/ Ezequiel 
Table 4. Variáveis resultantes do primeiro passo da análise estatística e as 8 selecionadas no segundo passo

\begin{tabular}{|c|c|c|c|c|}
\hline Variáveis retidas do $1^{\circ}$ passo & Domínio & $1^{\mathrm{a}}$ componente & $2^{\mathrm{a}}$ componente & $3^{\mathrm{a}}$ componente \\
\hline Pop c/ incapacidades (\%) & população & & & * \\
\hline Pop 0-14 (\%) & população & & & \\
\hline Pop 15-24 (\%) & população & & & \\
\hline Pop 25-64 (\%) & população & & & \\
\hline Pop 65-74 (\%) & população & & & \\
\hline Pop mais $75(\%)$ & população & & $*$ & \\
\hline Pop feminina (\%) & população & $*$ & & \\
\hline Pop masculina (\%) & população & & & \\
\hline Pop s/ escolaridade (\%) & população & $*$ & & \\
\hline Pop c/ $1^{\circ}$ ciclo (\%) & população & & & \\
\hline Pop c/ $2^{\circ}$ ciclo (\%) & população & & & \\
\hline Pop c/ $3^{\circ}$ ciclo (\%) & população & & & \\
\hline Pop c/ secundário (\%) & população & & & \\
\hline Pop c/ pós-secundário (\%) & população & & & \\
\hline Pop c/ superior $(\%)$ & população & & & \\
\hline Atropelamentos $\left(n^{\circ} / 100,000\right.$ habit $)$ & população & & & \\
\hline Edif s/ elevador $(\%)$ & habitação & & & \\
\hline Edif s/ entrada cadeira de rodas (\%) & habitação & $*$ & & \\
\hline Edif c/ necessidade reparação (\%) & habitação & & & \\
\hline Edif mt degradados (\%) & habitação & & & \\
\hline Edif antes $1919(\%)$ & habitação & & $*$ & \\
\hline Edif 1919-1945(\%) & habitação & & & \\
\hline Edif 1946-1970 (\%) & habitação & & & \\
\hline Edif 1971-1990 (\%) & habitação & & & \\
\hline Edif 1991-2011 (\%) & habitação & & & \\
\hline Edif exclusiv residenciais (\%) & habitação & $*$ & & \\
\hline Edif principal residenciais (\%) & habitação & & & \\
\hline Edif principal $\mathrm{n}$ residenciais (\%) & habitação & & & \\
\hline Compacidade meio urbano (Edif $\left./ \mathrm{km}^{2}\right)$ & habitação & & & $*$ \\
\hline
\end{tabular}

veis. Assim, numa apreciação à composição dos clusters em termos de variáveis foi possível traçar o seguinte perfil:

O Cluster 1 (designado como Polarizador e envelhecido) integra duas freguesias da margem sul e que são as que apresentam uma maior intensidade de ocorrências de incapacidades funcionais: Canha e Santiago. Para além de ser marcado por uma polarização de indivíduos com problemas ligados às incapacidades funcionais concentra ainda os indivíduos com mais de 75 anos e pouco escolarizados. Estas características do cluster permitem suspeitar que existe uma relação causa-efeito na conjugação de particularidades demográficas e sociais com a emergência das incapacidades funcionais. É ainda possível prolongar a ideia da importância do social quando se verifica que também as freguesias do Cluster 1 se destacam nos edifícios com quase um século ou mais, com todos os problemas de conservação e adequação que daí derivam. Final- mente, e para ajudar a compreender o facto de surgirem estas duas freguesias no mesmo cluster, verifica-se que a compacidade do meio urbano é aqui muito maior que em quaisquer outras, o que acaba por relativizar os problemas descritos atrás (Tabela 5; Fig. 4). O termo polarizador resulta desta concentração de problemas e de edificado e o envelhecido serve para destacar um dos aspetos que se consideram mais relevantes.

O Cluster 2 (Desqualificado e residencial) é o que integra mais freguesias (dez) sendo que, naturalmente, estas se localizam em vários enquadramentos territoriais no contexto metropolitano. Em todo o caso regista-se uma predominância da margem sul (sete freguesias) sendo que três se localizam no Arco Ribeirinho Sul e outras três na zona nascente da península de Setúbal. São cinco as variáveis que se destacam no seio deste cluster e marcam as respetivas dez freguesias que acolhe: uma menor proporção de população envelhecida; menor peso da popu- 


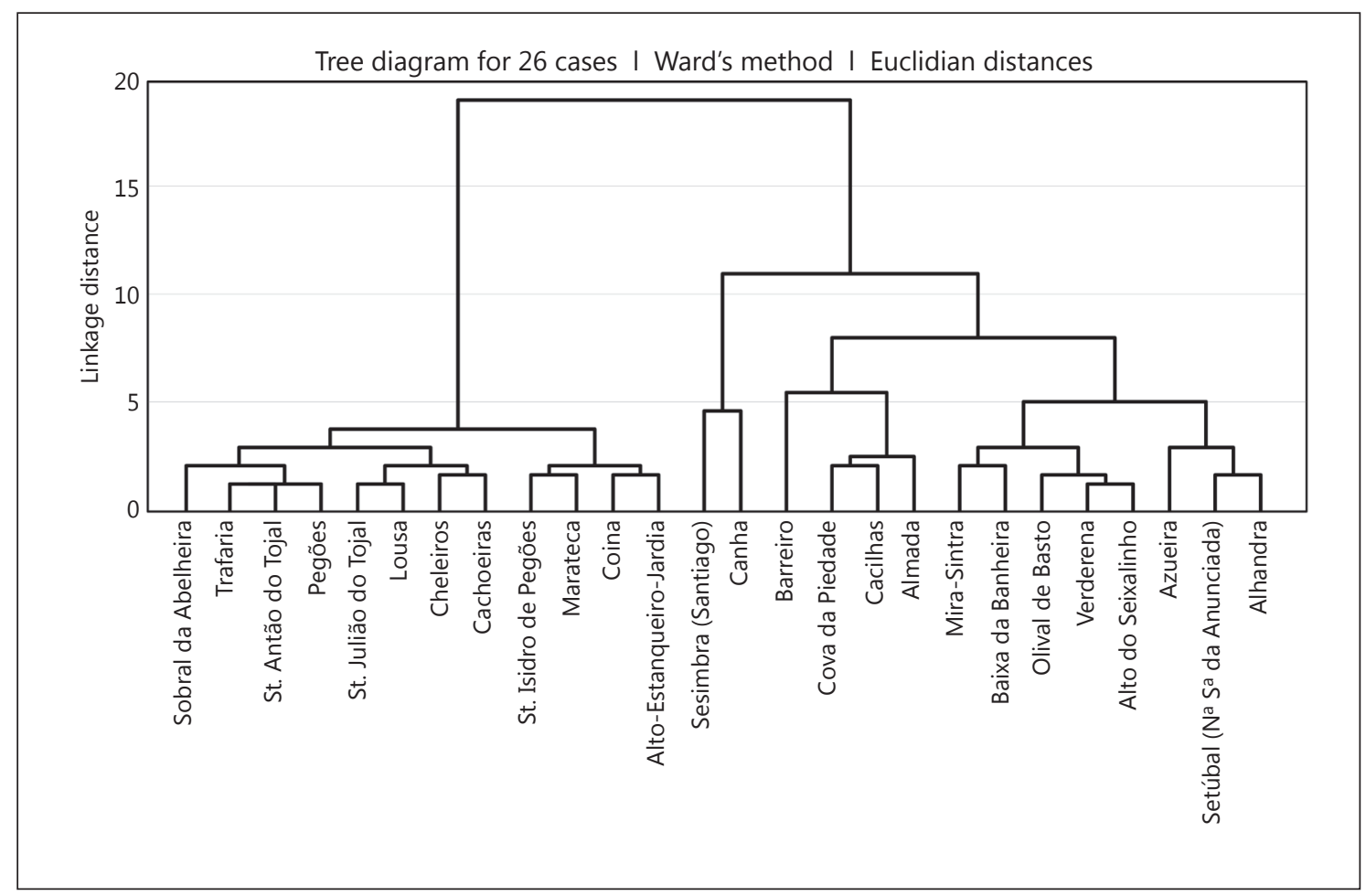

Fig. 3. Dendrograma da análise de clusters hierárquica das 26 freguesias (método de agregação de Ward).

lação feminina; população sem escolaridade o que reaviva as questões sociais já focadas no cluster anterior embora aqui recentradas sobre outros grupos etários que não os idosos; grande concentração de edifícios exclusivamente residenciais revelando muito sobre a limitada diversidade funcional destas freguesias; esta última característica e possivelmente a tipologia unifamiliar dos alojamentos pode ajudar a explicar a baixa proporção de edifícios sem entrada para cadeira de rodas. Neste cluster a concentração de incapacitados funcionais é semelhante à média sendo marcado por uma população adulta desqualificada e por um edificado dedicado sobretudo à habitação. Assim se explica o desqualificado e residencial da designação dada a este cluster;

O Cluster 3 (Antigo e rural) inclui seis freguesias sendo que cinco se localizam na margem norte. Essas cinco freguesias têm três facetas comuns: (i) terem uma pequena dimensão populacional (nenhuma tem mais de 4.000 residentes); (ii) terem uma fraca densidade territorial de ocorrências de incapacidades funcionais (todas abaixo de 70 por $\mathrm{km}^{2}$ ); (iii) persistirem nelas traços marcantes de ruralidade. As variáveis que o constituem permitem a caracterização feita e até alguma pormenorização ao nível do edificado. Com efeito, por um lado, a intensidade das incapacidades funcionais, embora importante, não permite inserir estas freguesias no grupo das mais gravosas; por outro lado, possuem edifícios muito antigos mas ainda assim com a qualidade suficiente para acolherem a cadeira de rodas (talvez pela tipologia) e ainda com uma baixa compacidade do meio urbano, relembrando a sugestão dos traços de ruralidade. A sua designação de antigo e rural surge, assim, da ausência das densidades urbanas e da maior presença de edifícios com quase um século ou mais;

O Cluster 4 (Pouco acessível e diverso) integra oito freguesias sendo que seis se localizam na margem sul e todas elas no Arco Ribeirinho. Note-se que as quatro freguesias com mais episódios de incapacidades (cada uma delas com mais de 4.000 ocorrências) e as sete freguesias com maior densidade territorial de ocorrências de incapacidades funcionais inserem-se neste cruzamento entre cluster e posicionamento territorial metropolitano. $\mathrm{O}$ registo deste cruzamento é um dado crucial uma vez que vem denunciar que é nas freguesias em que se concentram mais ocorrências que se encontram as condições de acessibilidades às edificações menos favoráveis, o que parece 


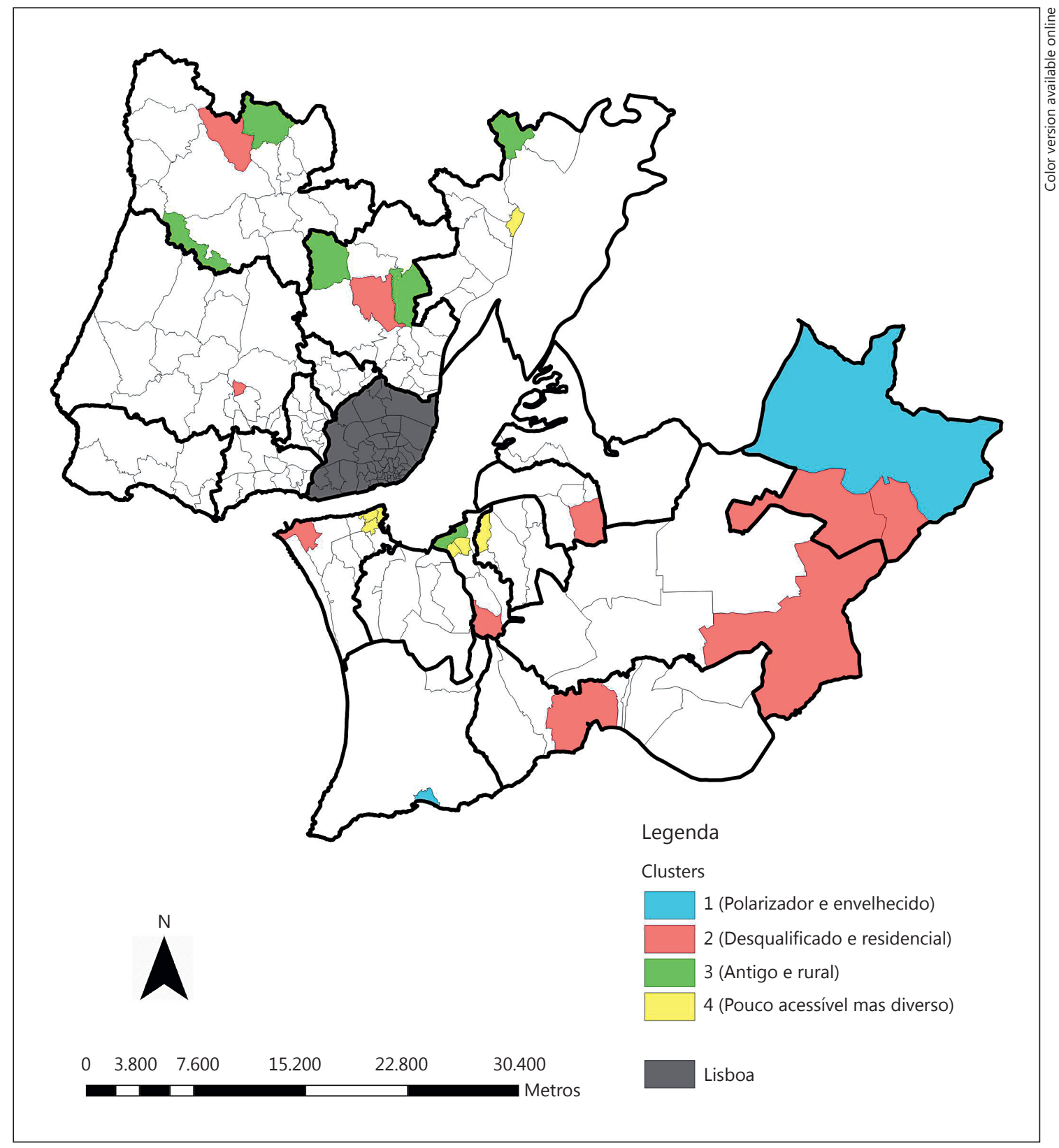

Fig. 4. Clusters e freguesias associadas.

indiciar que as oito freguesias incluídas neste cluster (e que concentram mais de 28.000 episódios de incapacidades) podem ser prioritárias nas intervenções a empreender. Estas freguesias são territórios com uma significativa diversidade funcional porque correspondem em larga medida a áreas urbanas tradicionais. Essa mesma tradição e a tipologia das edificações (edifícios de habitação coletiva) que a acompanha justifica o grande peso de edifícios sem entrada para cadeira de rodas. Existe ainda uma sobre-representação da população feminina e níveis de escolaridade apreciáveis.

Entendeu-se, desta forma, destacar este cluster como um dos que se apresenta menos acessível em cadeira de rodas e com grande diversidade quer na população residente quer na composição funcional. 
Table 5. Enquadramento metropolitano e tipificação por clusters das freguesias

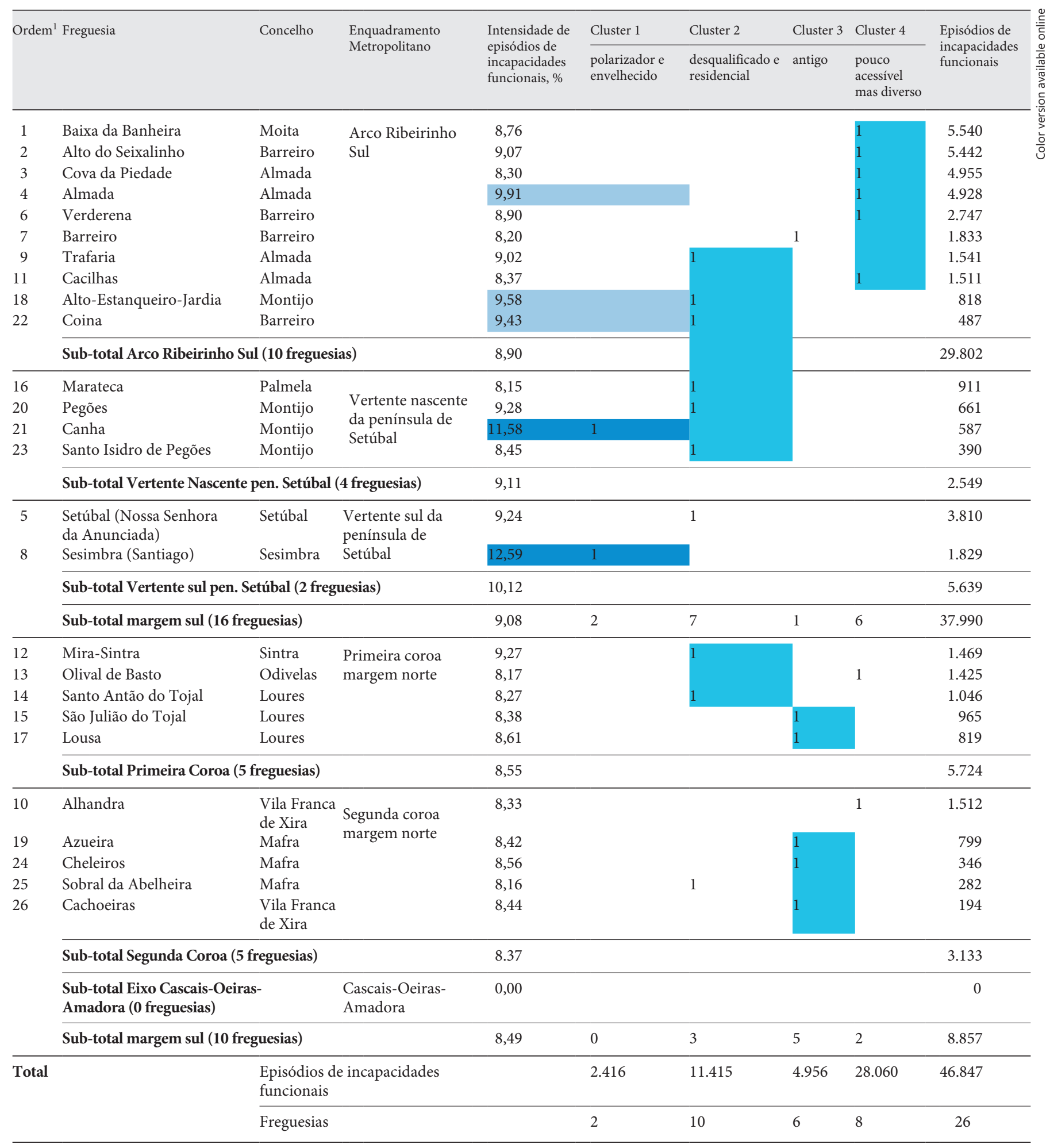

\footnotetext{
${ }^{1}$ Ordem decrescente de pop. com incapacidades.
} 


\section{Discussão}

Do trabalho desenvolvido verificou-se, em síntese, que das 158 freguesias suburbanas da AML apenas 26 revelaram uma taxa de risco bastante acima do esperado (acima da média + desvio padrão) na concentração de episódios de dificuldades em ouvir, ver e andar. Estas freguesias estão assimetricamente distribuídas: dez no norte e 16 no sul da AML.

Das variáveis recolhidas a análise estatística acabou por se centrar apenas em oito (População com incapacidades (\%), População com mais de 75 anos (\%), População feminina (\%), População sem escolaridade (\%), Edifícios sem entrada para cadeira de rodas (\%), Edifícios construídos antes de 1919 (\%), Edifícios exclusivamente residenciais (\%), Compacidade do meio urbano (Edif/ $\left.\mathrm{km}^{2}\right)$ ) que permitem descrever, de forma sintética, a realidade das 26 freguesias que concentram a maior intensidade de episódios realativos a incapacidades funcionais.

A análise de clusters aplicada a estas freguesias permitiu encontrar quatro grupos que se diferenciam em termos de características demográficas, sociais e do edificado: polarizador e envelhecido; desqualificado e residencial; antigo e rural; pouco acessível e diverso.

Estes resultados apresentam contributos interessantes quer no que respeita à distribuição das ocorrências das incapacidades funcionais na periferia de Lisboa, quer na determinação de uma tipologia de freguesias que combina variáveis individuais com variáveis urbanísticas.

As intervenções que as administrações central e local têm estado a desenvolver neste âmbito, embora importantes, decorrem sobretudo de imposições legais adoptadas em 2006 (Decreto-Lei no 163/2006, de 8 de Agosto) onde se definem as condições de acessibilidade a satisfazer no projeto e na construção de espaços públicos, equipamentos colectivos e edifícios públicos e habitacionais.

Todavia, é ainda possível elencar outras mudanças visíveis quer por intervenção dos municípios quer das freguesias. O planeamento, a mobilidade, o espaço público e a reabilitação urbana são os domínios que têm merecido atenção relevante. Vale a pena destacar, no caso destes domínios, a utilidade que tem tido a figura legal da Área de Reabilitação Urbana para quando os atores locais pretendem avançar com processos amplos e integrados de intervenção no edificado e no espaço público melhorando, designadamente, as condições de acessibilidade aos edifícios e até operando mudanças profundas no espaço público - circulação, mobilidade, acessibilidade. Veja-se os casos emblemáticos da Rua Cândido dos Reis em Cacilhas, Almada, ou na Avenida Santos Matos, Amadora
[27] mas que, no entanto, não fazem parte das 26 freguesias aqui consideradas de risco.

Todos estes esforços reveladores de uma preocupação de inclusão social ganharão em integrar um maior rigor na análise das áreas urbanas de modo a otimizar as respostas a conceber.

É por isso que os resultados obtidos são, em nosso entender, interessantes porque permitiram identificar as freguesias na AML (sem Lisboa) com maior densidade de problemas relacionados com as incapacidades funcionais dos seus residentes o que, depois, acaba por ter influência direta e profunda na forma como muitos deles têm de viver o território.

Reconhece-se que a pouca diversidade de indicadores urbanísticos possa ter constituído uma limitação importante ao alcance dos resultados obtidos mas também constituem um campo a desbravar em novos desenvolvimentos desta investigação. Ressalta-se também como aspecto a ter sempre presente na leitura dos resultados deste trabalho o fato de que foram avaliados os episódios de incapacidade funcional e não o número de pessoas com incapacidade funcional.

Os resultados obtidos com este estudo poderão ser ainda aprofundados (como os relacionados com a necessidade de hierarquizar as intervenções tendentes à melhoria do edificado e do espaço público de modo a dar prioridade às áreas que concentram os maiores problemas) se a escala de trabalho for a secção e a subsecção estatística e, assim, poderem ser analisadas ainda com mais detalhe as condições físicas do espaço público e edificado. Do mesmo modo poder-se-á considerar no futuro variáveis mais desagregadas de forma a identificar com maior detalhe o número de incapacidades por indivíduo.

\section{Conclusões}

Existe um conjunto relevante de conclusões que devem ser sublinhadas de modo a tornar claro o contributo do estudo para o conhecimento da periferia de Lisboa mas também para uma intervenção pública mais qualificada e objetiva.

Em primeiro lugar, ficou agora claro na espacialização suburbana dos episódios de incapacidade funcional que este território metropolitano possui uma grande heterogeneidade no que respeita à manifestação deste problema.

Em segundo lugar, percebe-se que existe um conjunto significativo de freguesias onde a manifestação dos episódios de incapacidade funcional é bastante mais acentuada que nas demais. 
No seio deste conjunto de 26 freguesias suburbanas é possível ainda identificar padrões distintivos quando essas incapacidades são conjugadas com a demografia, arquitetura e o urbanismo.
Finalmente, parece evidente que estas conclusões podem ser de grande utilidade na concepção e aplicação de políticas e ações visando a qualificação dos teritórios de maneira a trazer maior qualidade de vida a estes indivíduos.

\section{References}

1 Steels SK: Characteristics of age-friendly cities and communities: a review. Cities 2015;47: 45-52.

2 United Nations: World Population Ageing. New York, Department of Economic and Social Affairs Population Division, 2009.

3 World Health Organization, United Nations Children's Fund: Joint Monitoring Programme for Water Supply and Sanitation: Progress on Drinking Water and Sanitation: Special Focus on Sanitation. New York, UNICEF/Geneva, WHO, 2008.

4 Montegomery MR, Ezeh AC: The health of urban population in developing countries: an overview; in Galea S, Vlahov D (eds): Handbook of Urban Health: Populations, Methods and Practice. New York, Springer, 2005.

5 Beard JR, Petitot C: Ageing and urbanization: can cities be designed to foster active ageing? Public Health Rev 2010;30:136-142.

6 Galea S, Vlahov D: Urban health: evidence, challenges, and directions. Ann Rev Public Health 2005;26:341-365.

7 Galea S, Freudenberg N, Vlahov D: Cities and population health. Soc Sci Med 2005;60: 1017-1033.

8 Fobkter S, Grotz R: Everyday mobility of elderly people in different urban settings: the example of the city of Bonn. Urban Stud 2006; 33:353-377.

9 Philips DR, Siu O-L, Yeh AG, Cheng KHC: Ageing and the urban environment; in Andrews GJ, Phillips DR (eds): Ageing and Place. Abingdon, Routledge, 2005, pp 147-164.

10 Del Duca GF, Silva MC, Hallal PC: Incapacidade funcional para atividades básicas e instrumentais da vida diária em idosos. Rev Saúde Pública 2009;43:796-805.
11 International Transport Forum: Pedestrian Safety, Urban Space and Health. Paris, OECD Publishing, 2012.

12 Nogueira H: Pessoas pobres, lugares pobres, saúde pobre. Territórios amplificadores do risco na Área Metropolitana de Lisboa. Rev Estudos Demográficos 2009;45:29-47.

13 Macintyre S, Macdonald L, Ellaway A: Do poorer people have poorer access to local resources and facilities? The distribution of local resources by area deprivation in Glasgow, Scotland. Soc Sci Med 2008;67:900-914.

14 Ribeiro AI, Pires A, Carvalho MS, Pina MF: Distance to parks and non-residential destinations influences physical activity of older people, but crime doesn't: a cross-sectional study in a southern European city. BMC Public Health 2015;15:593.

15 Ribeiro AI, Mitchell R, Carvalho MS, de Pina MF: Physical activity-friendly neighbourhood among older adults from a medium size urban setting in Southern Europe. Prev Med 2013;57:664-670.

16 Macintyre S, Maciver S, Sooman A: Area, class and health: should we be focusing on places or people? J Soc Policy 1993;22:213234.

17 Chandola T: Spatial and social determinants of urban health in low, middle and high-income countries. Public Health 2012;126:259261.

18 Cummins S, Curtis S, Diez-Roux A, Macintyre S: Understanding and representing 'place' in health research: a relational approach. Soc Sci Med 2007;65:1825-1838.
19 Gonçalves J, Gomes M, Carvalho L, Ezequiel S: Não ouvir, não ver, não andar: incapacidade funcional e urbanismo nos subúrbios de Lisboa; in Santana P, Nossa P (coord): GeoSaúde2014 - 1 Congresso de Geografia da Saúde dos Países de Língua Portuguesa, Universidade de Coimbra, 21-24 de Abril de 2014. A Geografia da saúde no cruzamento de saberes. Coimbra, CEGOT, 2014. ISBN: 978989-98945-0-1:588-591.

20 Balsas C: Downtown resilience: a review of recent (re)developments in Tempe, Arizona. Cities 2014;36:158-169.

21 INE/INSRJ: Esperanças de vida sem incapacidade física de longa duração. Caderno Temático $\mathrm{n}^{\circ}$ 10, Instituto Nacional de Estatística/Instituto Nacional de Saúde Dr. Ricardo Jorge, Lisboa, 2000.

22 INE: O envelhecimento em Portugal: situação demográfica e sócio-económica recente das pessoas idosas. Lisboa, INE, 36, 2002.

23 Eurostat: Healthy life years statistics. Luxembourg, European Union, 2016 (consultado 7 Março 2017). Disponível em: http://ec.europa.eu/eurostat/statistics-explained/index. php/Healthy_life_years_statistics\#Further_ Eurostat_information.

24 Salvati L, Munafo M, Gargiulo Morelli V, Sabbi A: Low-density settlements and land use changes in a Mediterranean urban region. Landsc Urban Plan 2012;105:43-52.

25 Gonçalves J, Gomes MC, Ezequiel S, Moreira F, Ramos IL: Differentiating peri-urban areas: a transdisciplinary approach towards a typology. Land Use Policy 2017;63:331-341.

26 Hair JF, Anderson, RE, Tatham RL, Black WC: Multivariate data analysis. New York: Prentice-Hall International, 2010.

27 Gonçalves J, Abreu R, Costa A: Starting over: a focused vision in old suburbs of Lisbon. Urban Des Int 2015;20:130-143. 